\title{
Dependence of overcurrent failure modes of IGBT modules on interconnect technologies
}

\author{
Imran Yaqub ${ }^{1,2}$, Jianfeng $\mathrm{Li}^{1{ }^{1} *}$, Christopher Mark Johnson ${ }^{1}$ \\ ${ }^{1}$ Department of Electrical and Electronic Engineering, The University of Nottingham, \\ University Park, Nottingham NG7 2RD, United Kingdom \\ ${ }^{2}$ Dynex Semiconductor Limited, Doddington Road, Lincoln LN6 3LF, United Kingdom
}

\begin{abstract}
Insulated gate bipolar transistor (IGBT) modules which can fail to short circuit mode have great of applications in electricity network related fields. Single IGBT samples have been constructed with the standard Al wire bonding, flexible printed circuit board (PCB) interconnect and sandwich structure technologies. The overcurrent failure modes of the constructed IGBT samples have been tested under a range of energy levels, and the structures of the tested samples have been characterized with scanning electronic microscopy and threedimensional X-ray computed tomography imaging. The results obtained indicate that the IGBT samples constructed with the three interconnect technologies can fail to both open circuit mode and short circuit mode. The sandwich structure IGBT sample can fail to short circuit mode under an energy level of $750 \mathrm{~J}$ which can meet realistic industrial applications. The networked conductive phases within the solidification structure and the Sn-3.5Ag filled in the cracks within the residual Si IGBT are responsible for forming the conducting paths in the tested samples. Both liquid phase and gas phase can be formed and the highest temperature can reach the boiling point of $\mathrm{Si}$ even if the sandwich structure IGBT sample is tested with short circuit failure mode.
\end{abstract}

Keywords: Failure to short circuit; Failure to open circuit; Wirebond; Flexible PCB;

\footnotetext{
* Corresponding author. Tel.: +44 115846 6890; Fax: 441159515616.

E-mail address: Jianfeng.Li@nottingham.ac.uk
} 
Sandwich structure; Microstructure

\section{Introduction}

Insulated gate bipolar transistor ( IGBT) modules are widely used as switching devices in various applications such as traction motor drives, renewable energy, high voltage direct current links, pulse power systems, switch mode power supplies and uninterruptable power supplies etc. In those electricity network related applications, a preference for failure to short circuit behavior in the event of device destruction which is caused by unexpected overcurrent or overvoltage fault is one of the known requirements for the IGBT modules to meet the technological development. This is because in series connected strings of the IGBT modules where a level of redundancy can be employed, the strings can still function correctly in the event of the failure occurring in a single or several redundant modules, and the failed modules can be replaced in the next scheduled maintenance. This ability is especially important for the systems which are installed very remotely, at places which are not easy to access or where the cost of unscheduled maintenance is very high [1].

Interconnect is the important part of the packaging process for achieving failure to short circuit behavior of an IGBT module. This is because the failure is in general caused by extremely rapid electric-thermal energy dissipation in the module, while both the mechanical structure and the thermal and electric conducting paths of the module during the operation heavily depend on the interconnect technology. Al wire bonded interconnect is the standard technology which has been used for many years in the conventional power modules including IGBT modules. Because of limited ability to dissipate heat and relatively high parasitic inductance which often restricts the thermal and electrical performance, several alternative interconnect technologies have been proposed and under intensive investigation for overcoming this problem [2-9]. Of them, only the press pack technology has been used for developing a couple of the IGBT modules featuring failure to short circuit behavior. 
The first commercially available IGBT module which was claimed to have ability to fail to short circuit behavior was called Press-Pack IGBT and introduced by Westcode [9-11]. Another IGBT module which was reported to have ability to fail to short circuit behavior was called StakPak IGBT module and introduced by ABB $[12,13]$. Both IGBT modules were developed based on the press pack interconnect technology, and are complicated in mechanical structure and in manufacturing process. Also, in order to achieve uniform pressure distribution and uniform heat dissipation between the different IGBTs, all the components in the modules have to be very flat and precise which makes it very expensive to manufacture.

The present work is concerned with overcurrent failure modes of the IGBT modules constructed with three relatively simple interconnect technologies, including the standard Al wire bonding, flexible printed circuit board (PCB) and sandwich structure technologies $[8,14-$ 17]. The main aim is to investigate and find relatively simple and cost effective solution for design and manufacturing of the IGBT modules which feature failure to short circuit behavior. The specific objectives of this paper are: (i) to test the failure behaviors of the IGBT modules constructed with the three interconnect technologies; (ii) to demonstrate the ability of featuring failure to short circuit behavior for the sandwich structure IGBT module under realistic energy levels in the event of IGBT destruction; (iii) to characterize the microstructures of the tested IGBT modules with both failure to open circuit behavior and failure to short circuit behavior; and (iv) to provide insight into the phase changes of the component materials in the IGBT modules during the overcurrent testing.

\section{Materials and methods}

\subsection{Materials and sample preparation}

Instead of destroying the whole IGBT modules having complex structures, the samples of single IGBT modules have been constructed with the three interconnect technologies for 
the overcurrent testing. For all the samples, the substrate used is commercially available AlNbased direct bonded copper (DBC) substrate, which had two $\mathrm{Cu}$ islands on one side and one single $\mathrm{Cu}$ plate on the other side of the AlN ceramic tile. The thickness of the AlN ceramic tile was $1 \mathrm{~mm}$, and those of $\mathrm{Cu}$ islands and $\mathrm{Cu}$ plate on both sides were $0.3 \mathrm{~mm}$.

\subsubsection{Al wire bonded samples}

For preparing the samples with the Al wire bonding technology, the $13.5 \mathrm{~mm} \times 13.5$ $\mathrm{mm} \times 0.3 \mathrm{~mm} 1700 \mathrm{~V} / 50 \mathrm{~A} \mathrm{Si}$ IGBTs with central gate were obtained from Dynex Semiconductor Ltd (Lincoln, UK). They have $\sim 0.1 / 1 / 1 \mu \mathrm{m}$ thick Ti/Ni/Ag metallization on the collector or the back side and $\sim 5 \mu \mathrm{m}$ thick Al metallization on both the emitter and gate of i.e. the top side. During the assembling process, $100 \mu \mathrm{m}$ thick eutectic Sn-3.5Ag solder paste was first applied with stencil printing on each of the AlN-based DBC substrates. Then the Si IGBT die was placed on the printed solder paste, and the solder was reflowed in air at a peak temperature of $260{ }^{\circ} \mathrm{C}$ for 5 minutes. After this, the surface oxide of the DBC substrate was removed by applying a flux at $60{ }^{\circ} \mathrm{C}$ for one minute followed by rinsing with de-ionized water. Finally, $99.999 \%$ pure $375 \mu$ m diameter Al wire was bonded on both the top side of the IGBT and the DBC substrate using an ultrasonic bonding machine for achieving the necessary interconnection. Fig. 1 shows the photograph of one as-prepared IGBT sample constructed with the Al wire bonding technology.

\subsubsection{Flexible PCB interconnected samples}

For preparing the samples with the flexible PCB based interconnect technology, the $13.5 \mathrm{~mm} \times 13.5 \mathrm{~mm} \times 0.5 \mathrm{~mm} 2500 \mathrm{~V} / 50 \mathrm{~A}$ Si IGBTs with corner gate were obtained also from Dynex Semiconductor Ltd (Lincoln, UK). They have $\sim 0.1 / 1 / 1 \mu \mathrm{m}$ thick Ti/Ni/Ag metallization on the collector or the back side and $\sim 5 \mu \mathrm{m}$ thick Al metallization on the gate, and $\sim 5 / 0.1 / 1 / 1 \mu \mathrm{m}$ thick $\mathrm{Al} / \mathrm{Ti} / \mathrm{Ni} / \mathrm{Ag}$ metallization on the emitter of the top side. The flexible PCB was custom manufactured from Stevenage Circuits Ltd (Stevenage, UK). It consisted of 
$100 \mu \mathrm{m}$ thick polyimide sandwiched by $100 \mu \mathrm{m}$ thick $\mathrm{Cu}$ tracks on both sides. There were $\phi 1.2 \mathrm{~mm}$ and $\phi 1.6 \mathrm{~mm}$ through vias which connect the top and bottom side $\mathrm{Cu}$ tracks, and $\sim 4 / 0.1 \mu \mathrm{m}$ thick NiP/Au finish on the surfaces of the $\mathrm{Cu}$ tracks. Sintering of Ag nanoparticle was used for both the IGBT die attachment and bonding the flexible PCB to emitter side, and paste of the Ag nanoparticles was obtained from Cookson Electronics (South Plainfield, NJ 07080, USA).

During the assembling process, one piece of the flexible PCB was first placed and fixed on a piece of $25 \mu \mathrm{m}$ thick $\mathrm{Ag}$ foil with the same size. This was to blind vias on one side of the flexible PCB and improve the bonding of the sinterd Ag layer to the side walls of the vias. Then $100 \mu \mathrm{m}$ thick paste of $\mathrm{Ag}$ nanoparticles was applied on the top and filled into the through vias of the flexible PCB by using stencil printing, and dried at $130{ }^{\circ} \mathrm{C}$ for $30 \mathrm{~min}$. At the same time, a layer of $100 \mu \mathrm{m}$ thick paste of Ag nanoparticles was also printed on the the DBC substrate, and dried $130{ }^{\circ} \mathrm{C}$ for $30 \mathrm{~min}$. Following this, one Si IGBT were placed on the dried paste on the substrate, and then the flexible PCB with dried paste was aligned and put on the top side of the IGBT at one end and on another pad of the dried paste on the DBC substrate at the other end. A dummy Si die with the same thickness as the IGBT was also placed on top of the $25 \mu \mathrm{m}$ thick Ag foil on the flexible PCB at the end without the IGBT. This dummy Si die was used to mechanically compsensate the height of the flexible PCB, but not bonded to the Ag foil with any joining material. All the components were further fixed with kapton tape, and the sintering was carried out with a house made sintering press at a temperature of $250{ }^{\circ} \mathrm{C}$ and a pressure of $5 \mathrm{MPa}$ for 5 minutes. After the sintering, a $99.999 \%$ pure 375 um diameter $\mathrm{Al}$ wire was bonded on the corner gate of the IGBT for finalizing the sample preparation. Figs. 2 and 3 give the cross-sectional schematic and photograph of one as-prepared flexible PCB interconnected IGBT sample for the overcurrent testing. The dummy $\mathrm{Si}$ is not shown in Figs. 2 and 3 because it was easily removed after the sintering 
process.

\subsubsection{Sandwich structure samples}

Mechanical constraint was added to the flexible PCB interconnected IGBT sample to form the sandwich structure sample. This was achieved by placing a top DBC substrate similar to but slightly larger than the flexible PCB, and soldering two small pieces of DBC substrates between the top and bottom DBC substrates with eutectic Sn-3.5Ag solder paste to form the mechanical support and constraint. During the soldering process, a compressive force of $\sim 100 \mathrm{~N}$ was applied on the top DBC substrate with the house made press, and the solder was reflowed in air at a peak temperature of $260{ }^{\circ} \mathrm{C}$ for 5 minutes. Fig. 4 shows the cross-sectional schematic of the sandwich structure IGBT sample.

\subsection{Overcurrent testing}

\subsubsection{Testing procedure}

The overcurrent testing was carried out with a test rig schematically shown in Fig. 5. A 0 to $600 \mathrm{~V}$ XDC600-20 digital DC power supply made by Xantrax (Burnaby, BC, Canada) was connected to a capacitor bank which contained 9 Nippon (Tokyo, Japan) $6800 \mathrm{uF} 400 \mathrm{~V}$ aluminium electrolyte capacitors connected in parallel. An anti-parallel diode was connected across it as a free wheel diode. The positive terminal of the capacitor bank was connected to the collector terminal while the negative terminal of the capacitor bank was connected to the emitter terminal of the IGBT sample.

During the testing, the capacitor bank was pre-charged to a specified energy level by adjusting the voltage output of the power supply. The overcurrent was triggered by using a gate drive to turn on the IGBT. After turned on, the IGBT went into the saturation region, where the collector current reached its maximum value and stayed there until the IGBT's junction temperature exceeded its intrinsic or thermal limits after which the device braked down followed by a sudden influx of current from the capacitor bank. The current through 
and the voltage across the IGBT were recorded on the Tektronix DPO 7017 digital phosphor oscilloscope (Beaverton, OR, USA) by using a Rogowski coil manufactured by Power Electronic Measurements Ltd. (Nottingham, UK) and a Yokogawa (Taiwan, China) model 701926 high voltage differential probe respectively. The recorded residual voltage across the IGBT was used to judge whether the overcurrent testing of the IGBT resulted in open circuit failure mode (OCFM) or short circuit failure mode (SCFM).

It should be noted that the discharge profile during the testing was not controlled, and this was to mimic the failure of an IGBT in the real industrial scenario. This is because in reality, the discharge does not follow any profile rather than the natural discharge profile defined by the parasitic inductance, capacitance and resistance of discharge path. The IGBT was turned on by applying $+18 \mathrm{~V}$ to the gate terminal without any intentions to turn off the device or to modulate the discharge profile. This turn-on induced classic Type-II failure into the device (a failure which happens when the device is turned-on into an existing short circuit in the circuit).

\subsubsection{Estimation of realistic energy level in the event of IGBT destruction}

In a typical real industrial application, e.g. a voltage source dc to dc converter, the energy from the mains is stored locally in the capacitor bank known as a filter or line capacitor before delivering it to the IGBT. The value of this capacitor depends upon the application and can be in range starting from micron Farad to Farads. For an converter, operating at $1300 \mathrm{~V}$ having a DC link capacitor of $24 \mathrm{mF}$, the total energy stored in the system would be $E=\frac{1}{2} C V^{2}=20.3 \mathrm{~kJ}$. This is considered to be realistic amount of energy that the IGBT power module will face in real industrial applications. If this amount of energy gets dissipated in IGBT power module, it can cause explosion of the module with ejection of shrapnel [18]. If an IGBT power module is of 1500 A containing 30 IGBT dies (50 A each) connected in parallel this implies that there would be about 680 Joules of energy per device if 
the module fails uniformly. Hence for the present samples which all contain only one IGBT, the stored energy of about $750 \mathrm{~J}$ which is slightly higher than $680 \mathrm{~J}$ have been taken as a benchmark for the overcurrent testing.

\subsection{Structure characterization}

After the overcurrent testing, the failed samples constructed with the standard Al wire bonding technology and the flexible PCB interconnect technology were observed and analyzed using a Hitachi TM300 desktop scanning electronic microscope (SEM) and Quantax 70 energy-dispersive X-ray spectroscopy (EDXS) microanalysis system. Depending on the different samples, the morphologies and elemental compositions on the surfaces of the IGBTs and/or the microstructures and elemental compositions on the polished cross sections were observed and analyzed. For preparing the polished cross sections, the tested samples were first cut using a diamond saw, and then they were mounted within an epoxy resin which was later grinded and polished using first 600 grit size SiC paper down to $1 \mu \mathrm{m}$ diamond suspension.

The sandwich structure IGBT samples tested with both SCFM and OCFM were characterized using three-dimensional (3D) computed tomography (CT) imaging, carried out on an Xradia Versa XRM-500 system. This was to accurately calculate the volumes of the failure site, in particular, the amounts of the material that was removed due to melting and/or vaporization during the overcurrent testing. The volumes were calculated using imaging analysis method with the publically available software ImageJ. The calculated results will be used to provide insight into the phase change of the component materials and estimate the possible highest temperature.

\section{Results}

\subsection{Overcurrent testing}

\subsubsection{Al wire bonded samples}


Under the energy level of benchmark, $750 \mathrm{~J}$, pre-charged to the capacitor bank, the tested sample resulted in part evaporation and blow-out of all the $\mathrm{Al}$ wire bonds carrying the current. The OCFM due to such loss of all the Al wire bonds was observed when the energy level was reduced to 500, 250 and $125 \mathrm{~J}$. All the Al wire bonds were remained on the top of the tested IGBT, and SCFM was achieved when the energy level was further reduced to $62.5 \mathrm{~J}$.

Figure 6 presents representative waveforms of the recorded current through and the voltage across the IGBTs during the testing. A residual voltage of $\sim 40 \mathrm{~V}$ can be seen for the sample which failed to OCFM at the energy level of $500 \mathrm{~J}$, while a residual voltage of nearly zero can be seen from the sample which failed to SCFM at the energy level of $62.5 \mathrm{~J}$. Table 1 summarizes the peak current, current saturation time and failure mode from all the tested samples. For the Al wire bonded samples which resulted in OCFM under the testing energy level of 750 down to $125 \mathrm{~J}$, the peak current of 6000 A down to 600 A reached within the saturation time of $1 \mathrm{mS}$ to $7.5 \mathrm{mS}$. For the $\mathrm{Al}$ wire bonded sample which achieved SCFM under the testing energy level of $62.5 \mathrm{~J}$, the peak current of $1100 \mathrm{~A}$ reached within the saturation time of $3.8 \mathrm{mS}$.

\subsubsection{Flexible PCB interconnected samples}

The first sample was tested at $500 \mathrm{~J}$ and resulted in an OCFM. The second sample was tested at $250 \mathrm{~J}$, and resulted in SCFM. Then another two samples were tested at $375 \mathrm{~J}$ and 312.5 J. The one tested at $375 \mathrm{~J}$ was noted to have OCFM, while the one tested at $312.5 \mathrm{~J}$ achieved SCFM. Therefore, the energy required to achieve SCFM should be between $312.5 \mathrm{~J}$ and $375 \mathrm{~J}$.

The peak current, current saturation time and failure mode from all the tested flexible PCB interconnected samples are also listed in Table 2. It can be seen that under a similar testing energy level and peak current, the saturation time for the flexible PCB interconnected sample was clearly longer than that for the $\mathrm{Al}$ wire bonded sample. This can readily be 
attributed to the larger contact/conducting area in the flexible PCB interconnected sample which would have lower resistance and larger volume of the material for heat dissipation. As a result, a longer time was needed for the IGBT's junction temperature exceeded its intrinsic or thermal limits no matter whether it resulted in OCFM or SCFM.

\subsubsection{Sandwich structure samples}

Under the energy level of benchmark, $750 \mathrm{~J}$, pre-charged to the capacitor bank, the tested sandwich structure sample was observed to achieve SCFM. Then the sample was tested under double of that energy, i.e. $1500 \mathrm{~J}$, and it was noted that the sample acquired OCFM as the integrity of the structure was lost. Figure 7 presents the waveforms of the recorded current through and the voltage across the IGBTs of the two tested samples during the testing. A residual voltage of $\sim 40 \mathrm{~V}$ and nearly zero for the samples which failed to OCFM and SCFM are similar to those shown in Fig. 6 for the Al wire bonded samples. This reveals that under the resolution of the test rig, the residual voltages across the IGBTs which were used to judge OCFM and SCFM were independent of the interconnect technologies though much different energy levels could have been used.

In addition, it should be pointed out that for the majority of the test groups listed in Table 1, only one sample had been tested. However, for the Al wire bonded samples, two samples have been tested with SCFM under an energy level of $62.5 \mathrm{~J}$. For the sandwich structure samples, three samples had been tested with SCFM under $750 \mathrm{~J}$ and two samples had been tested with OCFM under $1500 \mathrm{~J}$. Therefore, in comparison with the Al wire bonded samples and flexible PCB interconnected samples, the sandwich structure samples would indeed improve the energy level to achieve SCFM.

\subsection{Structure characterization}

\subsubsection{Al wire bonded samples}

Figure 8 shows the photographs of two representative tested samples failed to OCFM 
and SCFM. It can be seen that all the Al wire bonds carrying the testing current had gone in sample which went to OCFM. Material removing of the Si IGBT also occurred on almost the entire surface of the tested vehicle, part of which was covering with solidification product, and part of which was covered with $\mathrm{Sn}-3.5 \mathrm{Ag}$ solder residual or even $\mathrm{Cu}$ residual on the DBC substrate. By contrast, all the Al wire bonds are still remained on top side of the IGBT in sample which went to SCFM. On the local region very close to the Al wire bonds, there was material removing and the surface of the IGBT was covered with solidification product. On the majority of the surface of the IGBT, the Si and the Al metallization on the Si were still intact.

Figure 9 presents the representative SEM images taken from the cross sections of the tested Al wire bonded samples with OCFM and SCFM. From the tested samples with OCFM, the solidification product surrounded by intact Si can be seen to occupy part space of the original $\mathrm{Si}$ and in contact with the $\mathrm{Sn}-3.5 \mathrm{Ag}$ solder residual under the original Si. EDXS analysis revealed that the white phases were less than the black phase of $\mathrm{Si}$ in the solidification product, and they mainly consisted of $\mathrm{Sn}$ plus minor $\mathrm{Al}$ and $\mathrm{Cu}$. As shown in Fig. 9 (b), the dendritic structure which resulted from the rapid and unstable solidification of the mixture of the molten $\mathrm{Si}-\mathrm{Sn}$ alloy with mixed $\mathrm{Al}$ and $\mathrm{Cu}$ had been produced and occupied part space of the original $\mathrm{Si}$ after the overcurrent testing. Sn-3.5Ag solder filled in the cracks in within the Si can also be seen, which probably came from the injection of the molten Sn3.5 Ag solder into the cracks caused by the explosion due to rapid solid-gas phase transformation during the overcurrent testing.

From the tested sample with SCFM, the Al wire bond was partially connected to the original $\mathrm{Si}$ and partially connected to the solidification product which was extending to the Si3.5Ag solder under the $\mathrm{Si}$ IGBT or the $\mathrm{Cu}$ of the DBC substrate. The scale of the solidification structure also in the form of dendritic structure was finer and smaller than those 
observed in the tested samples with OCFM. EDX analysis reveals that the white phases were further less than the black phase of Si in the solidification product, and they consisted of more or less similar amount of Sn and Al. There were also some cracks observed within the original $\mathrm{Si}$, and some of them were filled in with $\mathrm{Sn}-3.5 \mathrm{Ag}$ solder. A crater of $\sim 0.5 \mathrm{~mm}$ in size was further observed under the residual wire bond, occupying the space of the original Si and Sn3.5Ag solder there.

In addition, as pointed at by the arrows in Fig. 9 (a) and (c), it was the networked white phases consisting of $\mathrm{Sn}, \mathrm{Al}$ and $\mathrm{Cu}$, and the $\mathrm{Sn}-3.5 \mathrm{Ag}$ solder alloy filled in the cracks within the residual Si IGBT that formed the conductive channels in the spaces of the original Si IGBTs, and this will be further discussed below.

\subsubsection{Flexible PCB interconnected samples}

Figure 10 gives the photographs of two flexible PCB interconnected samples tested with OCFM and SCFM. In the sample tested with OCFM, most of the flexible PCB on the top of the IGBT had been blown off, and the bonding between the flexible PCB and the IGBT had been lost. In the sample tested with SCFM, only small part of the flexible PCB on the top of the IGBT had been blown off, and the bonding between the flexible PCB and the IGBT was still there.

Figures 11 and 12 present representative SEM images taken from the as-tested surfaces and the polished cross sections of the two samples shown in Fig. 10. It can be seen that crates with a depth of half to the entire thickness of the original Si IGBT were formed on the surfaces of both tested samples. The whole surfaces especially the walls of the craters in both samples were covered with a layer of solidification structure consisting of a mixture of black phase and white phase. Through careful observation, a primary phase consisting of black phase only and the coexisting eutectic structures consisting of both black phase and white phase could be identified, and hence the solidification structure was actually a hypo-eutectic 
structure. EDXS analysis revealed that the black phase was Si, and the white phase consisted of $\mathrm{Ag}$ plus minor $\mathrm{Cu}$ and $\mathrm{Al}$. Between the two samples, the one tested with OCFM under higher energy level contained higher percentage the white phase than the other sample tested with SCFM under lower energy level. In the sample tested with SCFM, the flexible PCB had reasonable bonding to the residual surface of the Si IGBT.

\subsubsection{Sandwich structure samples}

Figure 13 shows the photographs of the two sandwich structure samples after the overcurrent testing. It can be seen that the damage of the sample tested with OCFM under $1500 \mathrm{~J}$ was very catastrophic, and the sandwich structure had been disintegrated. By contrast, the top DBC was still fixed well in the sample tested with SCFM under $750 \mathrm{~J}$.

From the reconstructed 3D X-ray CT images, ten relatively small crates were visible in the sandwich sample tested with OCFM, and only one relatively large crater was observed in the sandwich sample tested with SCFM. Fig. 14 presents one cross-sectional view of the 3D X-ray CT images for both samples. For the sample tested with OCFM under energy level of $1500 \mathrm{~J}$, the craters had been through the entire thickness of Si IGBT, but just part of the top $\mathrm{Cu}$ track of the bottom DBC substrate. The sizes of the craters within the Si IGBT were approximately $0.5 \mathrm{~mm}$ to $4.0 \mathrm{~mm}$, while those within the top $\mathrm{Cu}$ track of the bottom $\mathrm{DBC}$ substrate were reduced approximately to $0.25 \mathrm{~mm}$ to $2 \mathrm{~mm}$ in the plane direction. From the reconstructed 3D images, the total volume of all the craters within the Si IGBT was calculated to be $13.6 \mathrm{~mm}^{3}$ and that within the $\mathrm{Cu}$ track to be $1.8 \mathrm{~mm}^{3}$. The latter volume also included the removed sintered $\mathrm{Ag}$ joint between the original IGBT and the original $\mathrm{Cu}$ track. Furthermore, the top layer of the IGBT with a thickness approximately of $0.14 \mathrm{~mm}$, equivalent to a volume of $25.1 \mathrm{~mm}^{3}$ was also removed during the overcurrent testing. Therefore, it can be said that a total volume of $38.7 \mathrm{~mm}^{3}$ from the Si IGBT had gone. 
For the sample tested with SCFM under energy level of $750 \mathrm{~J}$, the crater had been through thicknesses of both the Si IGBT and the top Cu track of the bottom DBC substrate. The average size of the crater within the Si IGBT was approximately $7.5 \mathrm{~mm}$, while its average size within the top $\mathrm{Cu}$ track of the bottom $\mathrm{DBC}$ substrate was reduced approximately to $3 \mathrm{~mm}$ in the plane direction. From the reconstructed 3D images, the volume of the crater within the Si IGBT was calculated to be $24.0 \mathrm{~mm}^{3}$ and that within the $\mathrm{Cu}$ track to be $4.4 \mathrm{~mm}^{3}$. The latter volume also included the removed sintered Ag joint between the original IGBT and the original $\mathrm{Cu}$ track.

In addition, it should be pointed out that in the as-prepared sandwich structure samples, the conductive paths were exactly the same as those in the as-prepared flexible PCB interconnected samples. Therefore, after the overcurrent testing, a layer of solidification structure consisting of a mixture of $\mathrm{Si}$ and $\mathrm{Ag}, \mathrm{Cu}$ and $\mathrm{Al}$ should also cover the surfaces and the walls of the craters formed in the sandwich structure samples.

\section{Discussion}

\subsection{Dependence of failure modes on interconnect technologies}

Under sufficient low energy level, SCFM can be achieved from the IGBT samples constructed with all the three investigated interconnect technologies. With increase in the energy level, SCFM would be changed to OCFM from the IGBT sample at a certain energy level depending on the used interconnect technology. The maximum energy levels for the three interconnect technologies to avoid OCFM are in the ascending order: Al wire bonding < flexible PCB interconnect < sandwich structure. The increase in this maximum energy level can be related to increase in the contact/conducting area, thermal mass and mechanical constraint in the interconnect technology. An energy level of $750 \mathrm{~J}$ which could meet realistic industrial applications had been achieved by using the sandwich structure IGBT sample 
ensuring SCFM. In comparison with the press pack interconnect technology which was used to develop the IGBT modules to have ability to fail to SCFM, the present result can provide a simpler and more cost-effective solution for those applications.

Rapid solidification structure had been observed in all the tested samples, which verifies the formation of liquid during the overcurrent testing. Electrical arc and explosion were always observed during testing all the samples despite to different degrees. The existence of the explosion reveals that a certain amount of high temperature gas must also have been produced. As shown in Fig. 9 (b), the crater under the residual Al wire bond observed in the Al bonded sample tested with SCFM indicated that the hottest region and the most serious damage occurred close to the Al wire bond, but under the surface of the Si IGBT. Therefore, Al wire bonds could at least partially avoid the contact and attack by the formed liquid and gas. This is probably the main reason why the $\mathrm{Al}$ wire bonds were still on the surface of the IGBT tested with SCFM under low energy level. Under higher energy levels, the volumes of the formed liquid and gas were larger enough to be in touch with the $\mathrm{Al}$ wire bonds, or the explosion caused by the high temperature gas was strong enough to break down the Al wire bonds. This can be used to explain why all the Al wire bonds had gone and the samples failed to OCFM.

The saturation time for the Al wire bonded samples tested with SCFM under an energy level of $62.5 \mathrm{~J}$ was shorter than those for the samples tested with OCFM under energy levels of $250 \mathrm{~J}$ and $125 \mathrm{~J}$. The reason why this occurred needs further investigation. One possibility may be related to the depth of the thermal overload breakdowns within the IGBT during the overcurrent testing. As mentioned previously, if the tested samples resulted in SCFM, the Al wire bonds stayed in-contact. It is thus reasonable to think that more energy could be dissipated in the IGBTs causing it to fail. By contrast, if the tested samples resulted in OCFM, the interconnect of the $\mathrm{Al}$ wire bonds broke down and thus more energy could be dissipated in 
the electric arc formed during the testing rather than in the IGBTs. Therefore, during the initial stage of the overcurrent injection, the energy was probably dissipated in relatively deep regions of the IGBTs when the samples were tested under $62.5 \mathrm{~J}$, while in the surface regions of the IGBTs close to the Al wire bonds when the samples were tested under higher energy levels. In this case, a little longer saturation time might be needed for the samples tested under $250 \mathrm{~J}$ and $125 \mathrm{~J}$ than the samples tested under $62.5 \mathrm{~J}$ to reach the juncture temperature limit. Another possibility may be associated with rates of temperature rise during the overcurrent testing. Generally speaking, a higher energy level would lead to a higher rate of the temperature rise, which would probably result in a higher juncture temperature limit. With appropriate combination of the rate of temperature rise and juncture temperature limit, it is possible for the samples tested under a lower energy level to have a saturation time longer than the samples tested under somewhat higher energy levels.

For the flexible PCB interconnected and sandwich structure samples, more energy is needed for the IGBT's juncture temperature exceeds its thermal limit because of the increase in contact/conducting area. On the other hand, the probability for the flexible PCB to partially be bonded to the surface of the tested IGBT would be increased because of the increased contact area between the flexible PCB and the IGBT, and/or the additional mechanical constraints. This is probably the reason why they improved the maximum energy for the IGBT sample to achieve SCFM and avoid OCFM.

\subsection{Conducting paths in the samples after the overcurrent testing}

Under high energy levels, the interconnect materials such as the Al wires and flexible PCB had gone after the overcurrent testing. It is hence obvious that the IGBT samples had OCFM because of loss of the continuity of the conducting paths. Under low energy levels when the IGBT samples tested with SCFM, the rapid solidification alloys covering the surfaces and walls of the formed craters and the Sn-3.5Ag filled in the cracks within the 
residual Si IGBT were the electrical connections existing between the residual interconnect materials and the residual Sn-3.5Ag solder joints.

In the rapid solidification alloys, the dendritic structure was observed in the Al wire bonded samples and the hypo-eutectic alloy of $\mathrm{Si}-\mathrm{Ag}, \mathrm{Al}$ and $\mathrm{Cu}$ was observed in the flexible PCB interconnected samples. The black phase Si existing in all these samples has low electrical conductivity, and the networked white phases consisting of $\mathrm{Sn}, \mathrm{Ag}, \mathrm{Al}$ and/or $\mathrm{Cu}$ have high electrical conductivity. Therefore, it was the networked white phases and the the Sn-3.5Ag filled in the cracks within the residual Si IGBT which formed the conductive channels to connect the residual Al wire bonds or flexible PCB and the residual Sn-3.5Ag solder joints together for forming the continuous conducting paths in those samples tested with SCFM.

\subsection{Phase changes occurring during the overcurrent testing}

From Fig. 7, it can be seen that the durations of the current pulse which passed through the IGBTs tested with SCFM under $750 \mathrm{~J}$ and OCFM under $1500 \mathrm{~J}$ were approximately 44 $\mathrm{mS}$ and $7 \mathrm{mS}$, respectively. This implies that all the energy had been dissipated in $44 \mathrm{mS}$ and $7 \mathrm{mS}$. Assuming that all the energy had been dissipated in the Si IGBT, the heat zone distance can be estimated by using the following Eq. (1) [19]:

$$
X=\sqrt{\frac{K_{S i} t}{\rho_{S i} C_{S i}}}
$$

Where $X$ is heat zone size, $t$ is time, and $K_{S i}$ is thermal conductivity, $\rho_{S i}$ is density and $C_{S i}$ is specific heat capacity of Si.

With the properties of $\mathrm{Si}$, the heat zone sizes $X=1.8 \mathrm{~mm}$ and $X=0.7 \mathrm{~mm}$ can be obtained from Eq. (1) for the durations of $44 \mathrm{mS}$ and $7 \mathrm{mS}$. Because of such heat zone sizes and the durations of the current pulse, most of the energy can be assumed to dissipate in the heat zones causing temperature rise in $\mathrm{Si}$ and closely nearby materials. For the purpose of simplification, the energy can be further assumed to be consumed for heating, melting and 
vaporizing the $4.4 \mathrm{~mm}^{3} \mathrm{Cu}$ and $24.0 \mathrm{~mm}^{3} \mathrm{Si}$ which initially occupied the space of the formed crater in the sample tested with SCFM, or heating, melting and vaporizing the $1.8 \mathrm{~mm}^{3} \mathrm{Cu}$ and $38.7 \mathrm{~mm}^{3} \mathrm{Si}$ which were removed in the sample tested with OCFM. Then the energy $Q_{b}$ needed to heat the $\mathrm{Cu}$ or $\mathrm{Si}$ up to their boiling point can be calculated with the following Eq. (2):

$$
Q_{b}=m C\left(T_{m}-T_{r}\right)+m \Delta H_{m}+m C\left(T_{b}-T_{m}\right)
$$

Where $m$ is mass, $C$ is specific heat capacity, $T_{r}$ is room temperature, $T_{m}$ is melting point, $T_{b}$ is boiling point and $\Delta H_{m}$ is latent heat of fusion. The energy $Q_{g}$ required for the $\mathrm{Cu}$ or $\mathrm{Si}$ to further become gas phase can be calculated with the following Eq. (3):

$$
Q_{g}=Q_{b}+m \Delta H_{b}
$$

While $\Delta H_{b}$ is latent heat of vaporization. With the thermal and physical properties listed in Table 2 [20-22], the energy $Q_{b}$ needed to heat $4.4 \mathrm{~mm}^{3} \mathrm{Cu}$ and $24.0 \mathrm{~mm}^{3}$ Si to their boiling points are respectively $47.2 \mathrm{~J}$ and $243.6 \mathrm{~J}$, and the energy $Q_{g}$ required for the $4.4 \mathrm{~mm}^{3} \mathrm{Cu}$ and $24.0 \mathrm{~mm}^{3} \mathrm{Si}$ to further become gas phase are respectively $236.2 \mathrm{~J}$ and $958.6 \mathrm{~J}$. By contrast, the energy $Q_{b}$ needed to heat $1.8 \mathrm{~mm}^{3} \mathrm{Cu}$ and $38.7 \mathrm{~mm}^{3}$ Si to their boiling points are respectively $19.3 \mathrm{~J}$ and $392.8 \mathrm{~J}$, and the energy required to $Q_{g}$ required for the $1.8 \mathrm{~mm}^{3} \mathrm{Cu}$ and $38.7 \mathrm{~mm}^{3}$ Si to further become gas phase are respectively $96.6 \mathrm{~J}$ and $1545.7 \mathrm{~J}$.

Indeed, a certain amount of the liquid formed during the overcurrent testing had been used to form the hypo-eutectic alloy of $\mathrm{Si}-\mathrm{Ag}, \mathrm{Al}$ and $\mathrm{Cu}$ which covered the surface and the side wall of the crater. However, its volume should be significantly smaller than the volume of the crater itself. Therefore, based on the above calculated values of $Q_{b}$ and $Q_{g}$, it is reasonable to say that both liquid phase and gas phase had been formed, the energy levels of $750 \mathrm{~J}$ and $1500 \mathrm{~J}$ are enough to vaporize certain amounts of $\mathrm{Si}$, and the highest temperature reached the boiling point of $\mathrm{Si}, 3265^{\circ} \mathrm{C}$, during the overcurrent testing of the sandwich structure samples. 
As aforementioned, a certain amount of high temperature gas must have been produced during testing all the samples. Similar estimation of the energy required for a certain amount of solid $\mathrm{Si}, \mathrm{Cu}, \mathrm{Al}$ and $\mathrm{Ag}$ to become gas phase can be applied to all the tested samples. As an approximation, it is reasonable to say that for all the samples tested under energy levels of 500 $\mathrm{J}$ and above, the highest temperatures should be similar to the boiling point of $\mathrm{Si}, 3265^{\circ} \mathrm{C}$, as estimated for the sandwich structure sample tested under $750 \mathrm{~J}$. The different energy levels used during testing these samples resulted in different amounts of Si gas and different sizes of the craters formed within the Si IGBTs. For those samples tested under lower energy levels, the highest temperatures in the $\mathrm{Al}$ wire bonded samples should at least reach the boiling point of $\mathrm{Al}, 2519^{\circ} \mathrm{C}$, and those in the flexible PCB interconnected samples should at least reach the boiling point of $\mathrm{Ag}, 2162{ }^{\circ} \mathrm{C}$.

\section{Conclusions}

Based on the above results and discussion, the following conclusions are drawn:

1) Depending on the energy levels applied during the overcurrent testing, the IGBT samples constructed with the three interconnect technologies can have both OCFM and SCFM.

2) The standard Al wire bonded IGBT sample can fail to SCFM under very low energy level. The flexible PCB interconnect and sandwich structure technologies can increase the energy levels for the IGBTs to achieve SCFM.

3) The sandwich structure IGBT sample can achieve SCFM under an energy level of $750 \mathrm{~J}$ which can meet realistic applications (as defined in section 2.2.2), and thus can provide a simpler and more cost-effective solution than the press pack technology for those applications.

4) The continuous conducting paths in those samples tested with SCFM is formed by the networked white phases within the solidification structure and the Sn-3.5Ag filled in 
the cracks within the residual Si IGBT which formed the conductive channels to connect the residual Al wire bonds or flexible PCB and the residual Sn-3.5Ag solder joints together.

5) Both liquid phase and gas phase can be formed and the highest temperature can reach the boiling point of $\mathrm{Si}$ when the sandwich structure IGBT samples are tested with both SCFM and OCFM.

\section{Acknowledgements}

Imran Yaqub would like to thank Dynex Semiconductor Limited for sponsoring his $\mathrm{PhD}$ study and providing power devices for this work. The authors gratefully acknowledge the support of the Innovative Electronics Manufacturing Research Centre (IeMRC) funded by the UK Engineering and Physical Sciences Research Council (EPSRC) through research grant $\mathrm{EP} / \mathrm{H} 03014 \mathrm{X} / 1$.

\section{References}

[1] J. Bing, S. Xueguan, E. Sciberras, C. Wenping, H. Yihua, V. Pickert. Multiobjective Design Optimization of IGBT Power Modules Considering Power Cycling and Thermal Cycling. Power Electronics, IEEE Transactions 2015;30:2493-2504.

[2] C. Luechinger. Ribbon Bonding - A Scalable Interconnect for Power QFN Packages. Proceedings of 9th Electronics Packaging Technology Conference 2007;47-54.

[3] J. Yin, Z. Liang, J.D. van Wyk. High Temperature Embedded SiC Chip Module (ECM) for Power Electronics Applications. IEEE Transactions on Power Electronics 2007;22:392-398.

[4] J.F. Li, A. Castellazzi, T.X. Dai, M. Corfield, A. Solomon, C.M. Johnson. Built-in reliability design of highly integrated solid-state power switches with metal bump 
interconnects. IEEE Transactions on Power Electronics 2015;30:2587-2600.

[5] G.Q. Lu, X. Liu, S. Wen, J.N. Calata, J.G. Bai. Strategies for improving the reliability of solder joints on power semiconductor devices. Soldering and Surface Mount Technology 2004;16:27-40.

[6] K. Weidner, M. Kaspar. Planar Interconnect Technology for Power Module System Integration. Integrated Power Electronics Systems (CIPS) 2012;459-463.

[7] C. Göbl, J. Faltenbacher. Low temperature sinter technology die attachment for power electronic applications. Integrated Power Electronics Systems (CIPS) 2010;10.1:1-5.

[8] N. Pluschke and P. Beckedahl. Novel packaging technology for power modules. Industrial Electronics (ISIE), IEEE International Symposium 2012;420-424.

[9] F. Wakeman, W. Findlay, G. Li. Press-pack IGBTs, semiconductor switches for pulse power. Pulsed Power Plasma Science, 2001;2:1051-1054.

[10] F. Wakeman, K. Billett, R. Irons, M. Evans. Electromechanical characteristics of a bondless pressure contact IGBT. Applied Power Electronics Conference and Exposition $1999 ; 1: 312-317$

[11] F. Wakeman, W. Findlay, L. Gangru. Press-pack IGBTs, semiconductor switches for pulse power. Pulsed Power Plasma Science 2001;2:1051-1054.

[12] S. Eicher, M. Rahimo, E. Tsyplakov, D. Schneider, A. Kopta, U. Schlapbach, et al. $4.5 \mathrm{kV}$ press pack IGBT designed for ruggedness and reliability. Industry Applications Conference 2004;3:1534-1539.

[13] S. Gunturi, D. Schneider. On the operation of a press pack IGBT module under short circuit conditions. Advanced Packaging, IEEE Transactions 2006;29:433-440.

[14] C. Göbl, J. Faltenbacher. Low temperature sinter technology die attachment for power electronic applications. Integrated Power Electronics Systems (CIPS) 2010;1-5. 
[15] U. Scheuermann. Reliability of Planar SKiN Interconnect Technology. Integrated Power Electronics Systems (CIPS) 2012;1-8.

[16] S. Haque, X. Kun, L. Ray-Lee, C.T.A. Suchicital, L. Guo-Quan, D.J. Nelson, et al. An innovative technique for packaging power electronic building blocks using metal posts interconnected parallel plate structures. Advanced Packaging, IEEE Transactions 1999;22:136-144.

[17] C.M. Johnson, C. Buttay, S.J. Rashid, F. Udrea, G.A.J. Amaratunga, P. Ireland, et al. Compact Double-Side Liquid-Impingement-Cooled Integrated Power Electronic Module. Power Semiconductor Devices and IC's 2007;53-56.

[18] S. Gekenidis, E. Ramezani, H. Zeller. Explosion tests on IGBT high voltage modules. Power Semiconductor Devices and ICs 1999;129-132.

[19] E. Marín. Characteristic dimensions for heat transfer. Latin-American Journal of Physics Education 2010; 4:56-60.

[20] W.W. Sheng, R.P. Colino, Power Electronic Modules: Design and Manufacture, CRC Press LLC, Florida, USA, 2005.

[21] A. Zéanh, O. Dalverny, M. Karama, E. Woirgard, S. Azzopardi, A. Bouzourene1, et al. Thermomechanical Modelling and Reliability Study of an IGBT Module for an Aeronautical Application. Thermal, Mechanical and Multiphysics Simulation and Experiments in Micro-Electronics and Micro-Systems, EuroSimE 2008.

[22] A. Zeanh, O. Dalverny, M. Karama, A. Bouzourene. Lifetime and reliability assessment of AlN substrates used in harsh aeronautic environments power switch modules. Advanced Materials Research 2010;112:113-127. 
Table 1 Summary of the results of the overcurrent testing from all the tested IGBT samples

\begin{tabular}{lccccc}
\hline & $\begin{array}{c}\text { Energy } \\
(\mathrm{J})\end{array}$ & $\begin{array}{c}\text { Voltage } \\
(\mathrm{V})\end{array}$ & $\begin{array}{c}\text { Peak Current } \\
(\mathrm{A})\end{array}$ & $\begin{array}{c}\text { Saturation time } \\
(\mathrm{mS})\end{array}$ & Failure Mode \\
\hline Al wire bonded & 750 & 156 & - & - & OCFM \\
samples & 500 & 128 & 6000 & 1 & OCFM \\
& 250 & 90 & 1800 & 5 & OCFM \\
& 125 & 63 & 600 & 7.5 & OCFM \\
& 62.5 & 45 & 1100 & 3.8 & SCFM \\
& & & & & \\
Flexible PCB & 500 & 128 & 6000 & 10.8 & OCFM \\
interconnected & 375 & 110 & 4600 & 14.8 & OCFM \\
samples & 312.5 & 101 & 1100 & 39.0 & SCFM \\
& 250 & 90 & - & - & SCFM \\
& & & & & \\
Sandwich & 1500 & 221 & 17500 & 2.0 & OCFM \\
structure samples & 750 & 156 & 9000 & 3.0 & SCFM \\
\hline
\end{tabular}

Table 2 Thermal and physical properties of $\mathrm{Cu}$ andv $\mathrm{Si}$ used to calculate the energy required for the phase changes

\begin{tabular}{lllllll}
\hline & $\begin{array}{l}\rho \\
\left(\mathrm{kg} / \mathrm{m}^{3}\right)\end{array}$ & $\begin{array}{l}\mathrm{C} \\
(\mathrm{J} / \mathrm{kg})\end{array}$ & $\begin{array}{l}\mathrm{T}_{\mathrm{m}} \\
\left({ }^{\circ} \mathrm{C}\right)\end{array}$ & $\begin{array}{l}\mathrm{T}_{\mathrm{b}} \\
\left({ }^{\circ} \mathrm{C}\right)\end{array}$ & $\begin{array}{l}\Delta \mathrm{H}_{\mathrm{m}} \\
(\mathrm{kJ} / \mathrm{kg})\end{array}$ & $\begin{array}{l}\Delta \mathrm{H}_{\mathrm{b}} \\
(\mathrm{kJ} / \mathrm{kg})\end{array}$ \\
\hline $\mathrm{Cu}$ & 8960 & 385 & 1085 & 2562 & 205 & 4730 \\
$\mathrm{Si}$ & 2329 & 750 & 1414 & 3265 & 1926 & 12800 \\
\hline
\end{tabular}

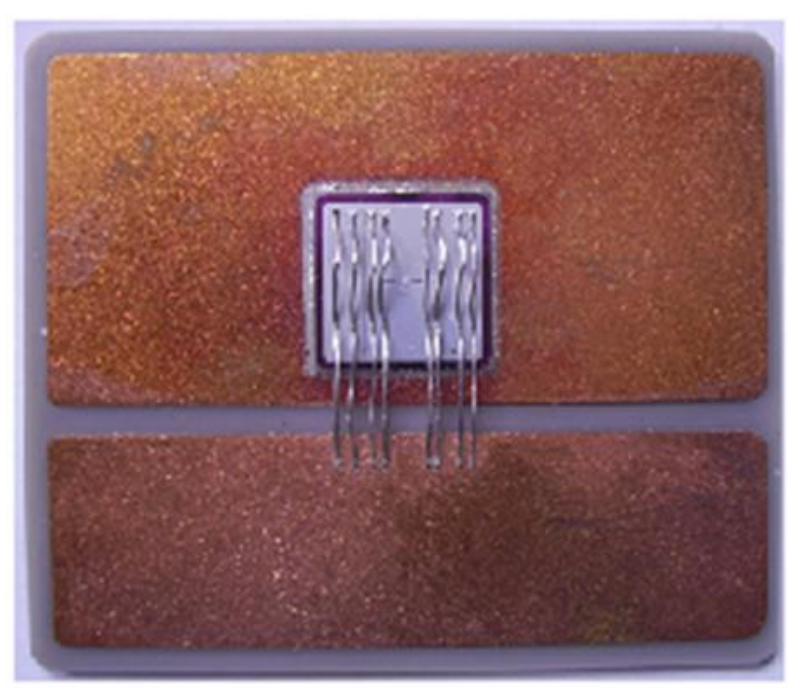

Fig. 1 Photograph of one as-prepared IGBT sample constructed with the AL wire bonding technology for the overcurrent testing. 


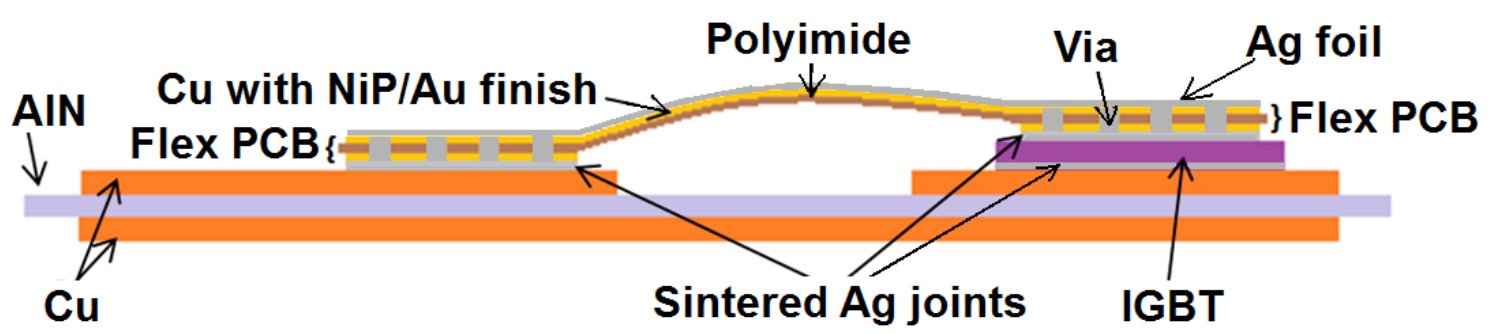

Fig. 2 Cross-sectional schematic of the flexible PCB interconnected IGBT sample (not to scale).

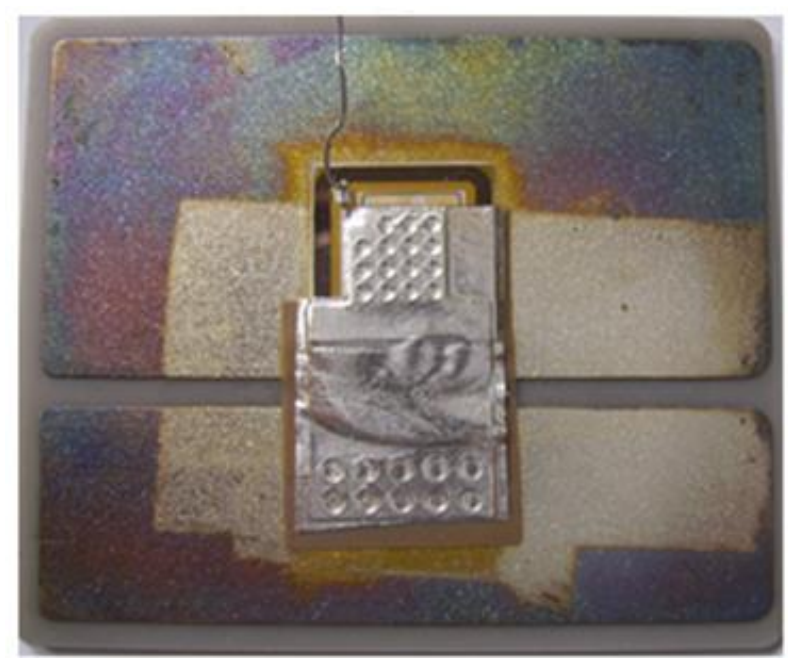

Fig. 3 Photograph of one as-prepared flexible PCB interconnected IGBT sample for the overcurrent testing.

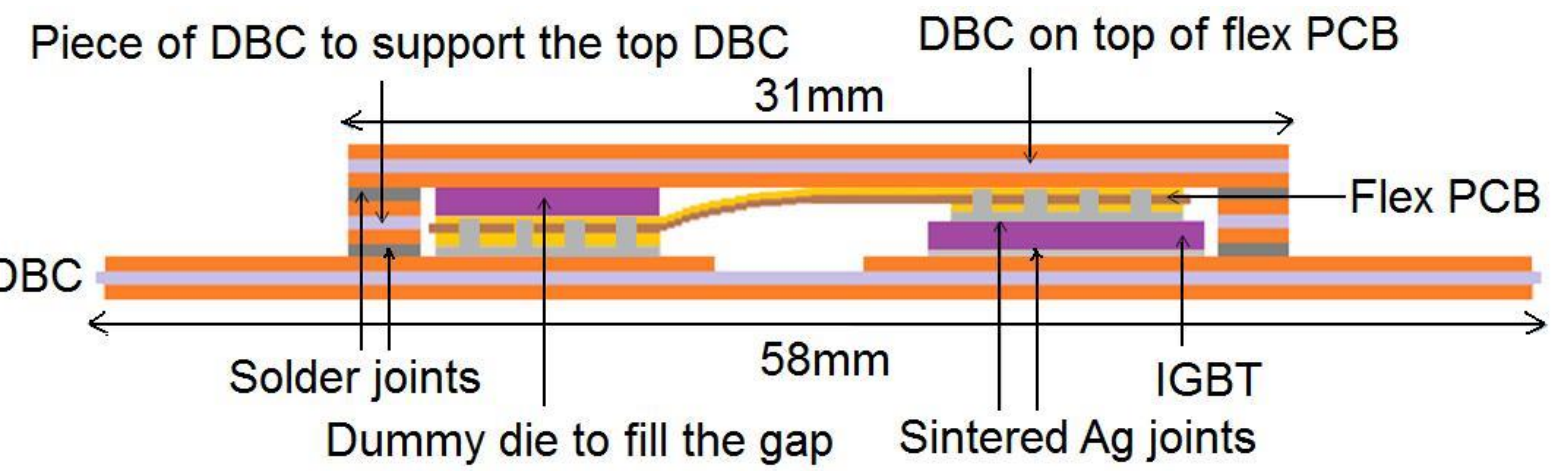

Fig. 4 Cross-sectional schematic of the sandwich structure IGBT sample (not to scale). 


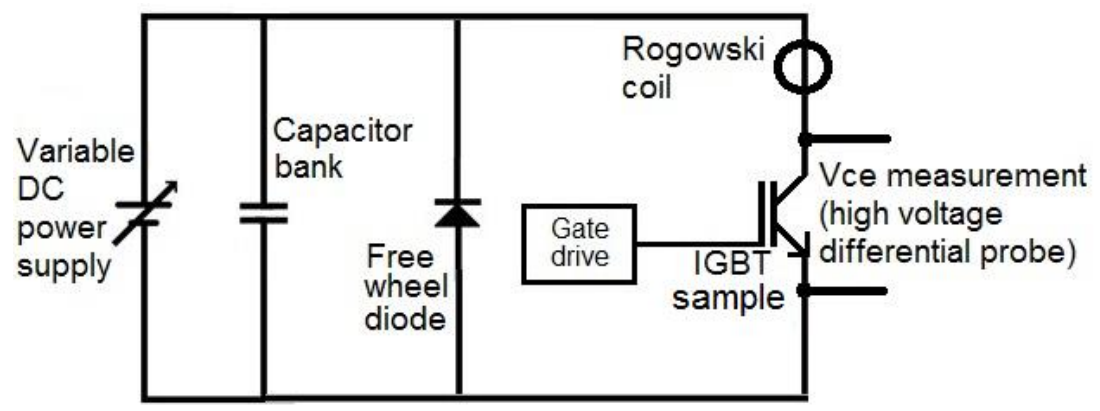

Fig. 5 Electrical circuit diagram of overcurrent testing.

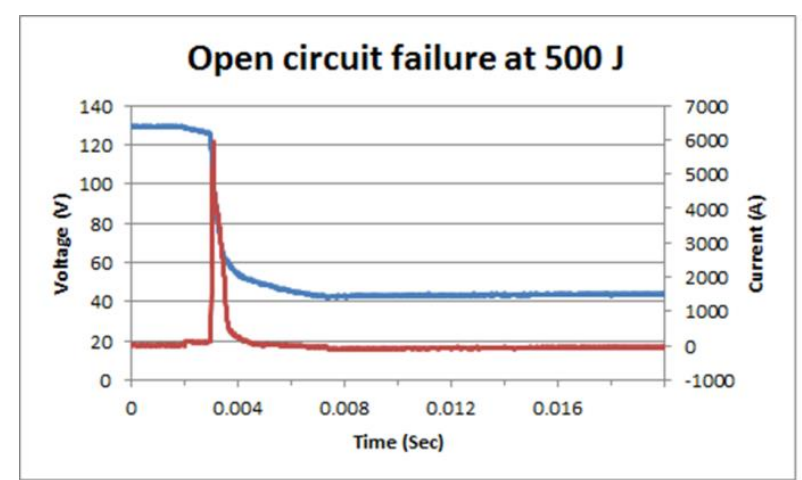

(a)

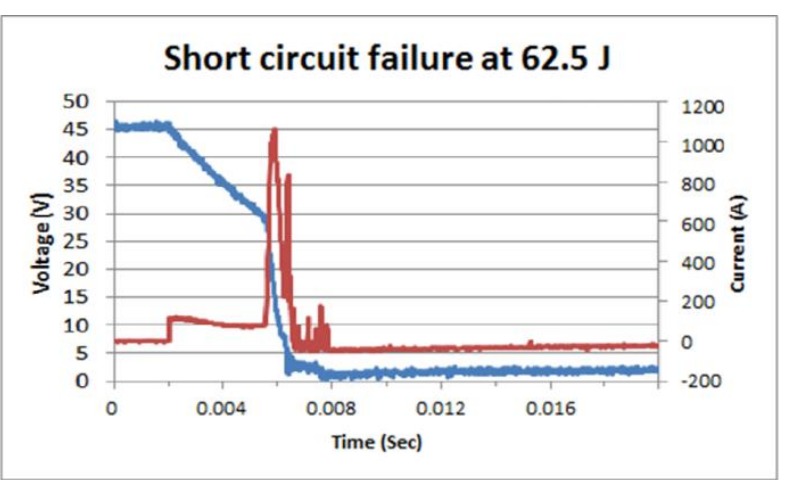

(b)

Fig. 6 Voltage and current waveforms of the Al wire bonded sample tested at: (a) $500 \mathrm{~J}$; and (b) $62.5 \mathrm{~J}$.

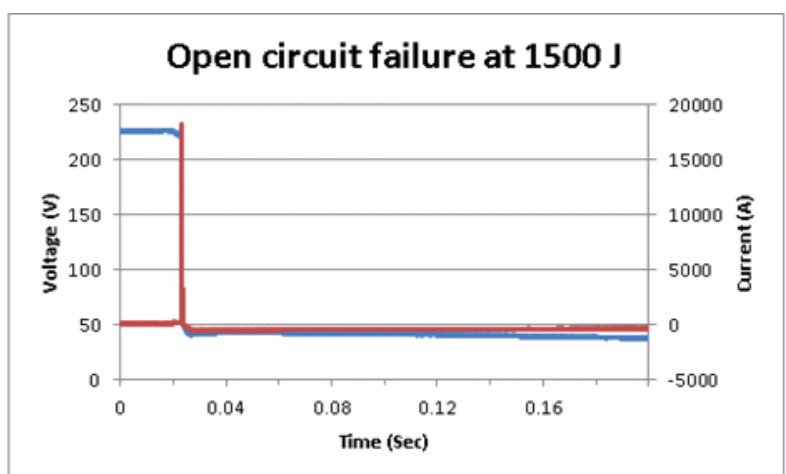

(a)

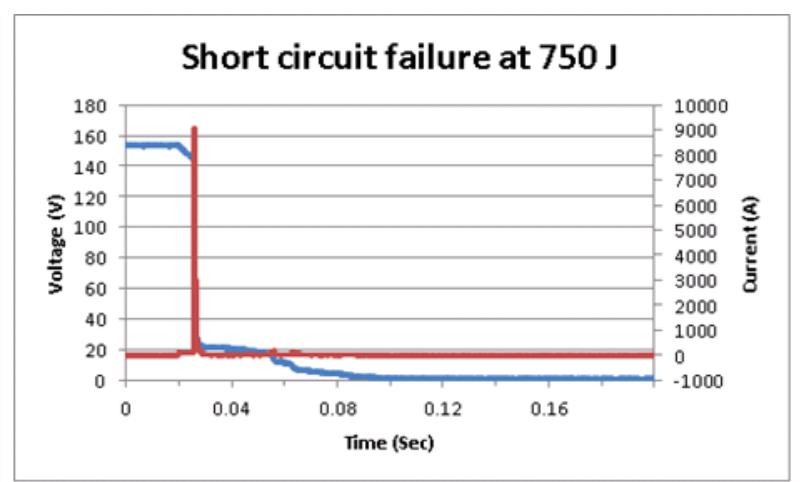

(b)

Fig. 7 Voltage and current waveforms of sandwich structure samples tested at: (a) $1500 \mathrm{~J}$; and (b) $750 \mathrm{~J}$. 


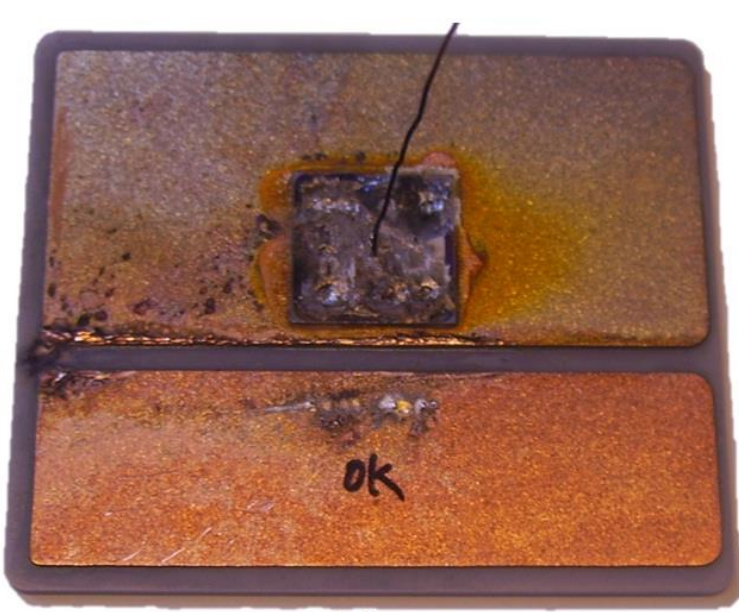

(a)

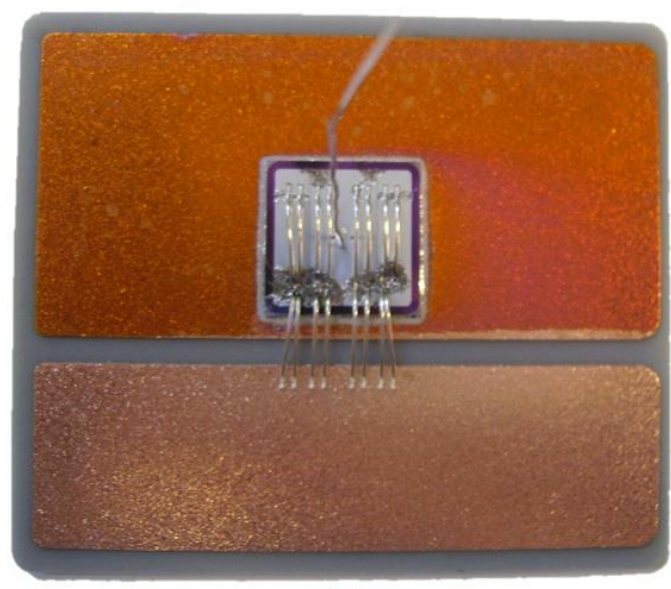

(b)

Fig. 8 Photographs of the Al wire bonded samples tested at: (a) $500 \mathrm{~J}$, OCFM; and (b) $62.5 \mathrm{~J}$, SCFM.

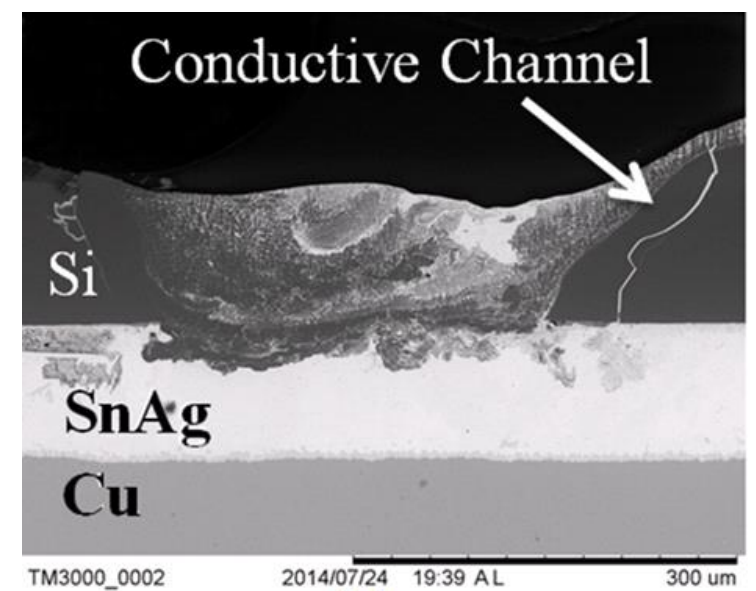

(a)

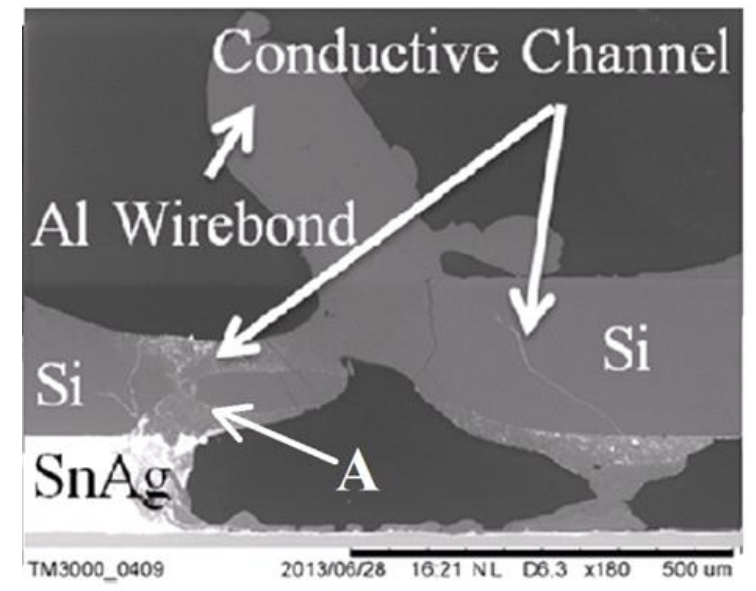

(c)

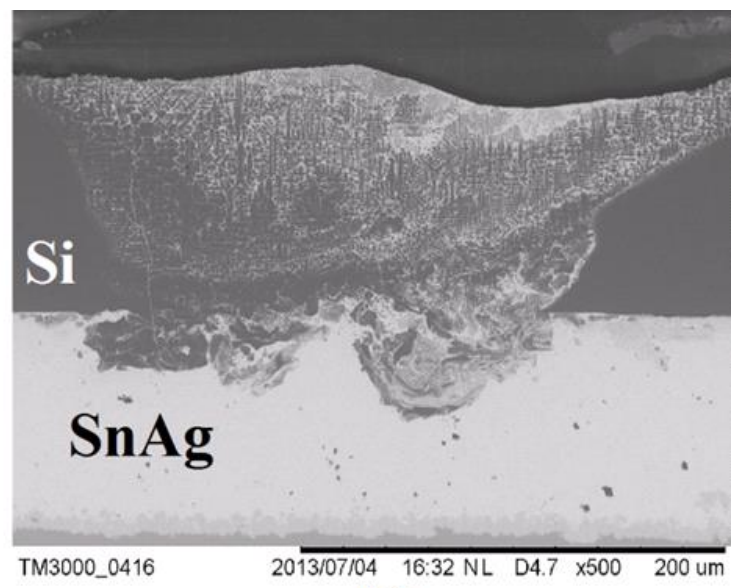

(b)

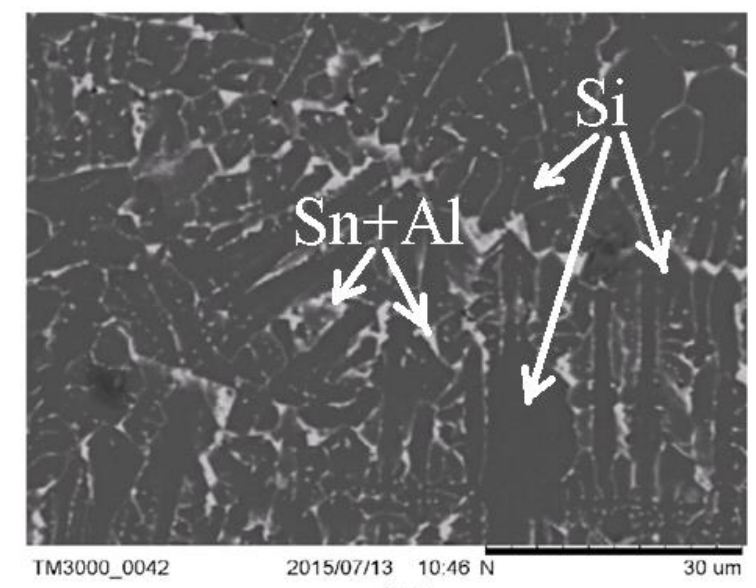

(d)

Fig. 9 SEM images taken from the polished cross sections of the Al wire bonded samples tested at: (a) $500 \mathrm{~J}$, OCFM; (b) $500 \mathrm{~J}$, OCFM, another location; (c) $62.5 \mathrm{~J}, \mathrm{SCFM}$; and (d) enlarged view around point $\mathrm{A}$ in (c). 


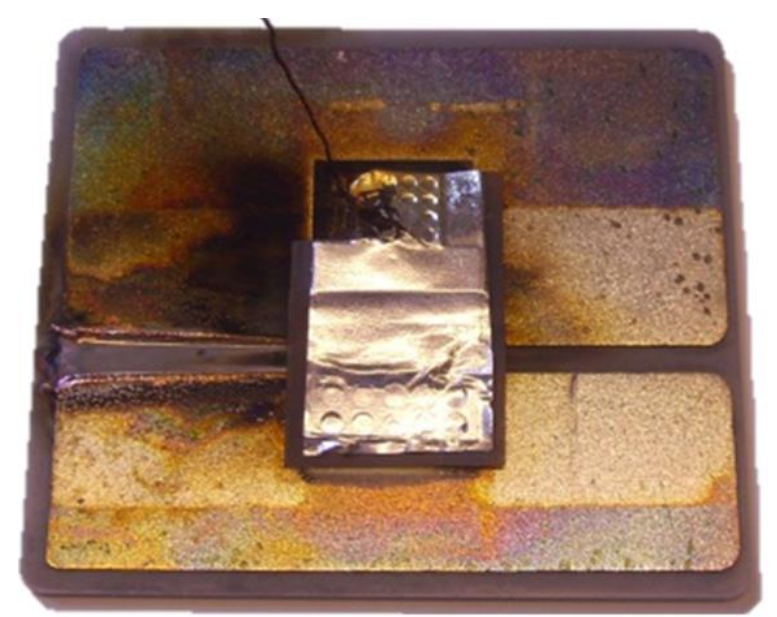

(a)

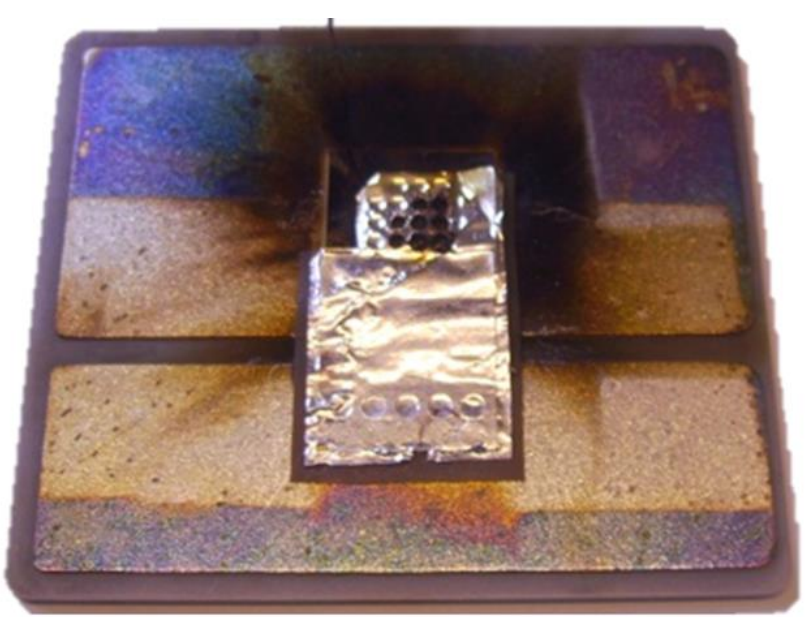

(b)

Fig. 10 Photographs of the flexible PCB interconnected samples tested at: (a) $500 \mathrm{~J}$, OCFM; and (b) $312.5 \mathrm{~J}$, SCFM.

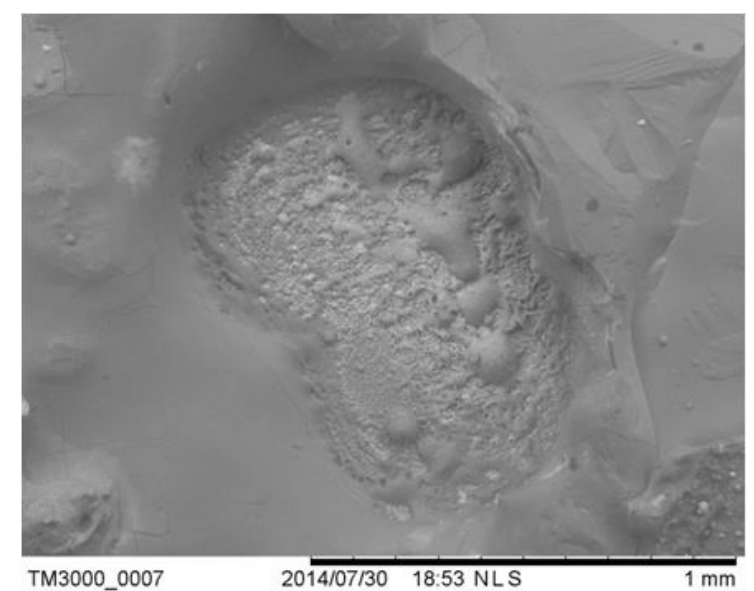

(a)

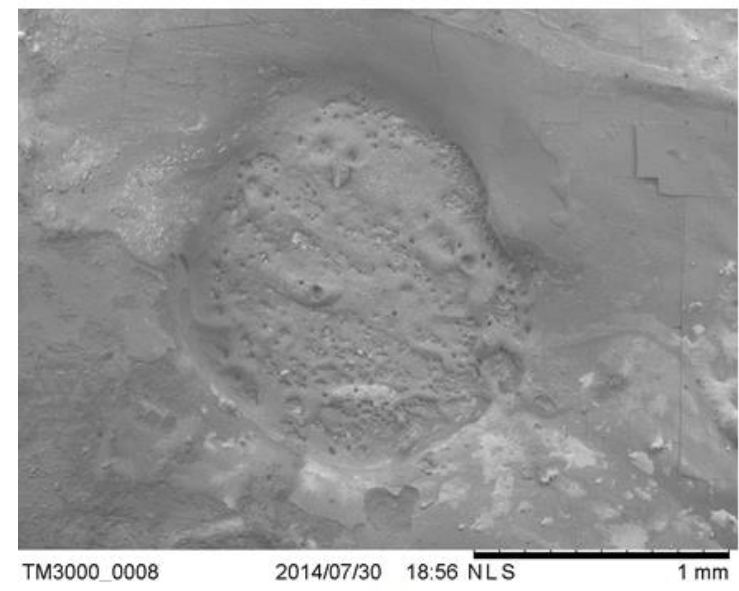

(c)

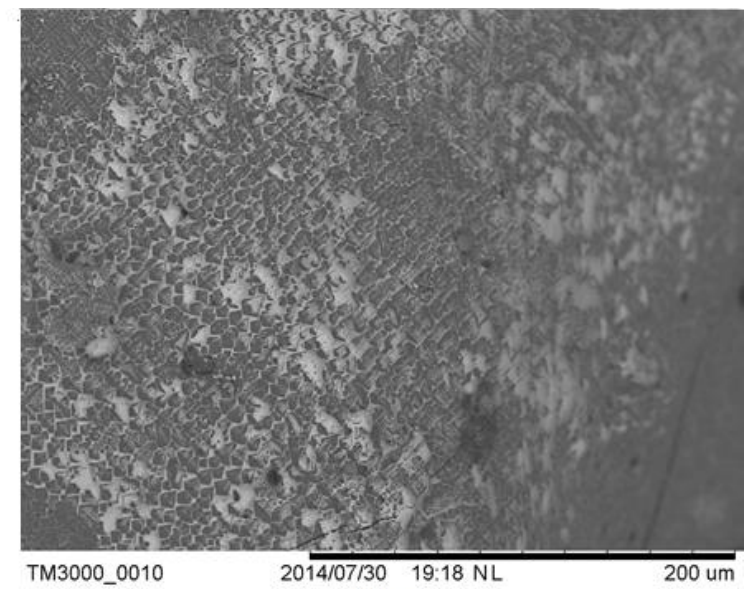

(b)

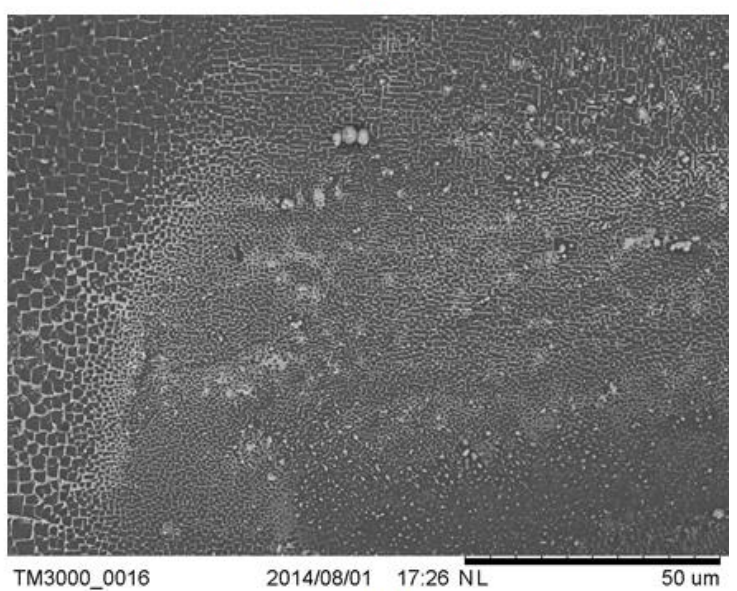

(d)

Fig. 11 SEM images taken from the surfaces of the flexible PCB interconnected samples tested at: (a) $500 \mathrm{~J}$, OCFM; (b) enlarged local view of (a); (c) $312.5 \mathrm{~J}, \mathrm{SCFM}$; and (d) enlarged local view of (c). 


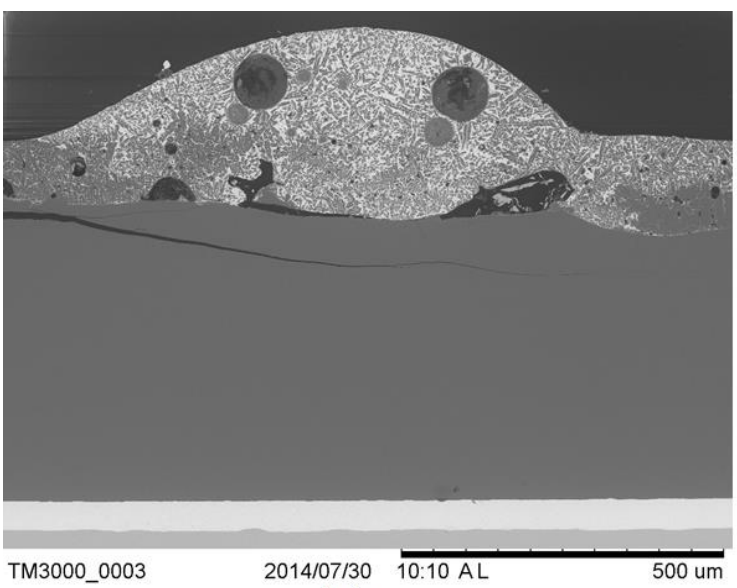

(a)

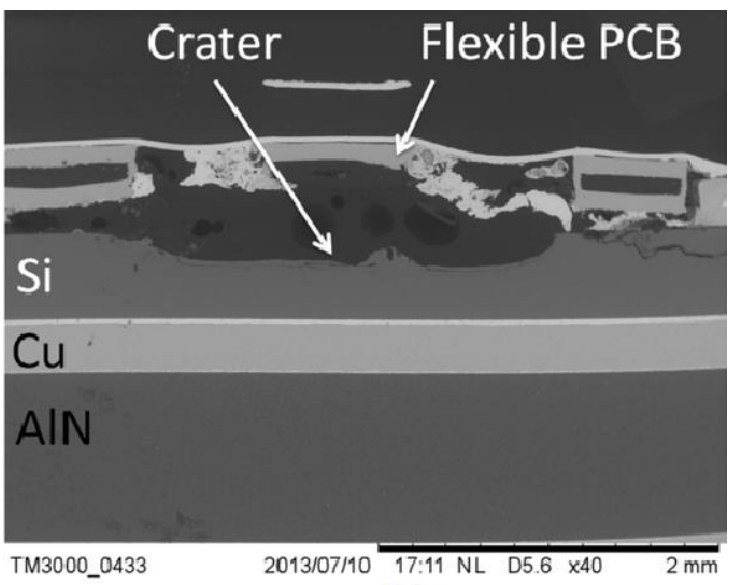

(b)

Fig. 12 SEM images taken from the polished cross sections of the flexible PCB interconnected samples tested at: (a) $500 \mathrm{~J}$, OCFM; and (b) $312.5 \mathrm{~J}$, SCFM.

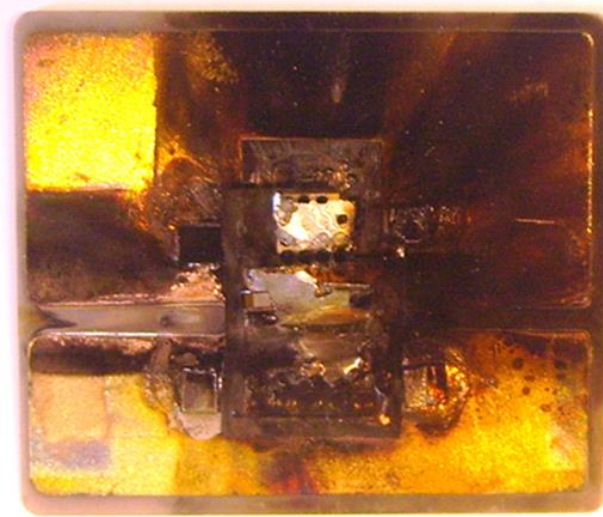

(a)

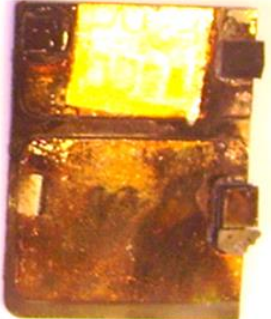

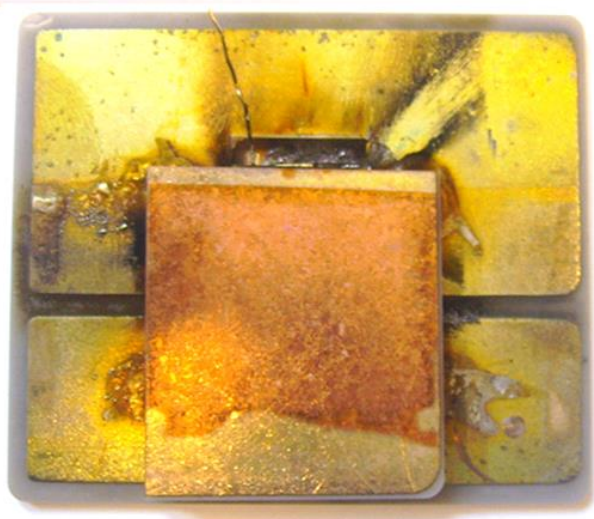

(b)

Fig. 13 Photographs of the sandwich structure samples tested at: (a) $1500 \mathrm{~J}$, OCFM; and (b) $750 \mathrm{~J}$, SCFM. 


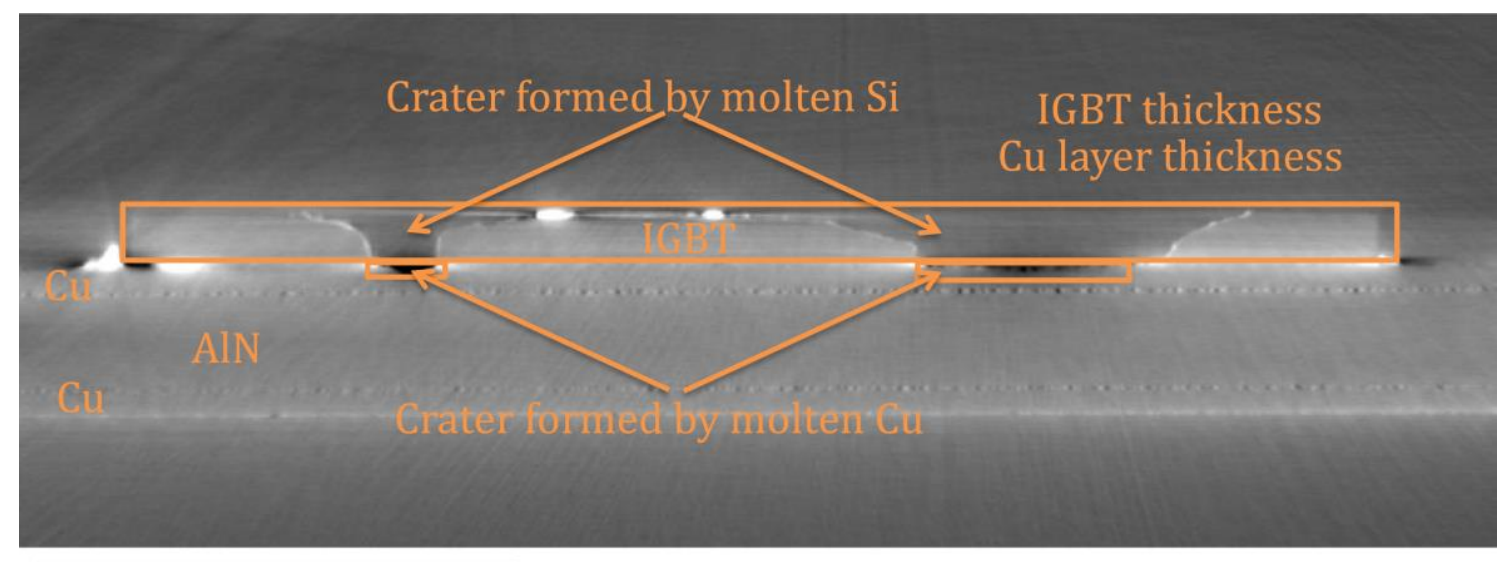

$5000 \mu \mathrm{m}$

(a)

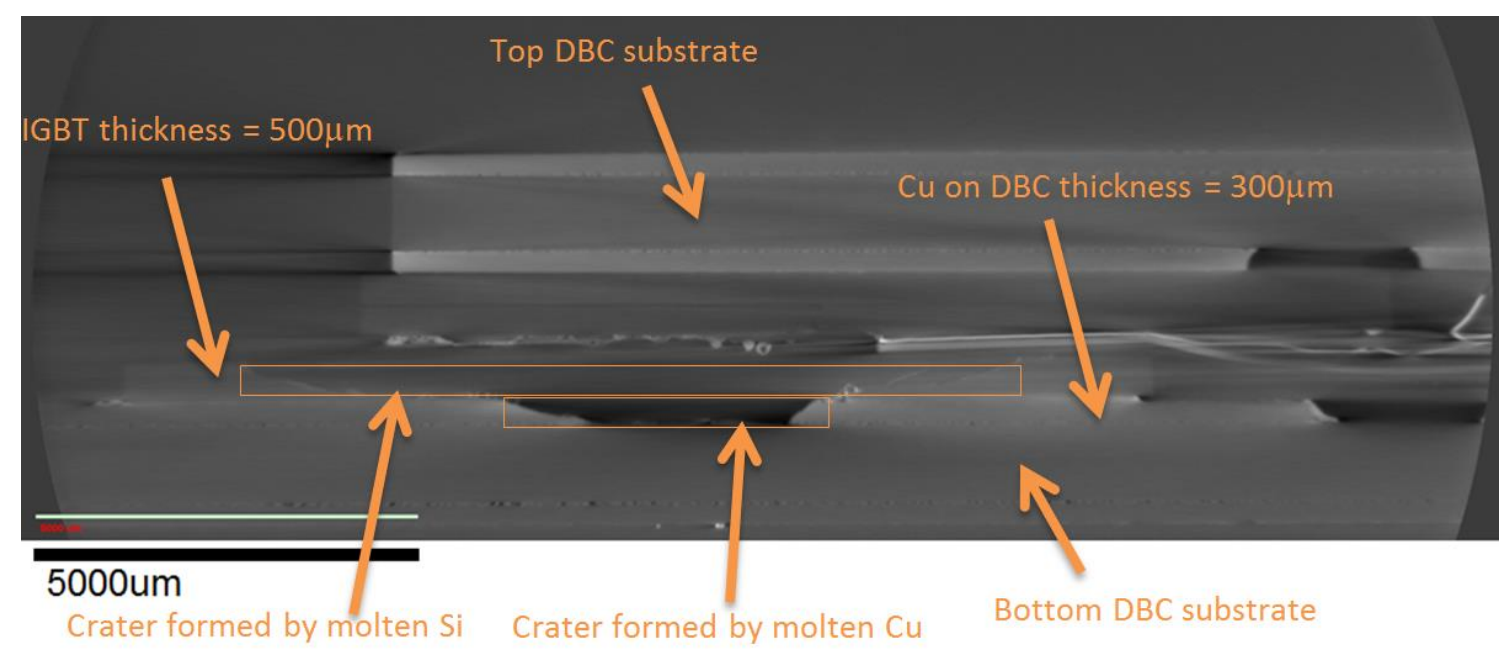

(b)

Fig. 14 Cross-sectional view selected from the reconstructed 3D X-ray CT images taken from the sandwich structure samples tested with: (a) OCFM under $1500 \mathrm{~J}$, and (b) SCFM under 750 $\mathrm{J}$. 